\title{
Epistemic Justification without Virtue: An Intermittent Rainman Dilemma for Ernest Sosa's Virtue Condition
}

\section{Eric Roark \\ University of Missouri-Columbia}

Abstract: This paper attempts, via proposing a dilemma, to expose a serious difficulty in Ernest Sosa's account of epistemic justification which he advocates in Epistemic Justification: Internalism vs. Externalism, Foundations vs. Virtues. In his account Sosa endorses a dual commitment to non-inferential unmediated foundational epistemic justification and his "virtue condition." By proceeding through a number of cases I argue that Sosa, given his endorsement of non-inferential unmediated foundational justification, must ascent to the conclusion that a person who has an intermittent rainman-like ability is foundationally justified to believe, for instance, that "this many speckled hen has forty-eight speckles." This result, taken in isolation, need not prove troubling for Sosa. The trouble, as I illustrate throughout the paper, for Sosa results when we try to wed this above commitment of non-inferential unmediated foundationally justified belief with his commitment to his virtue condition.

Ernest Sosa argues in Epistemic Justification: Internalism vs. Externalism, Foundations vs. Virtues ${ }^{1}$ that, in order for a belief $\mathrm{P}$ to be epistemically justified, $P$ must satisfy conditions of safety and virtue. In explicating both of these key notions Sosa writes:

'Laurence Bonjour and Ernest Sosa, Epistemic Justification: Internalism vs. Externalism, Foundations vs. Virtues (MA; 2003). 
If a faculty operates to give one a belief, and thereby a piece of direct knowledge, one must have an awareness of one's belief and its direct source, and the virtue of that source both in general and specific instance. Hence it must be that in the circumstances one would (most likely) believe $P$ only if $P$ were the case, i.e., one's belief must be safe; . . And, finally, one must grasp that one's belief non-accidentally reflects the truth of $P$ through accepting an indication of $P$, thus manifesting a cognitive virtue. $^{2}$

And further Sosa makes explicit that, "B is a justified belief only if B is a belief acquired through the exercise of one or more epistemic virtues." I shall refer to this principle as Sosa's virtue condition.

In this paper I will argue, that, contra Sosa, a justified belief B need not be a belief acquired through the exercise of one or more epistemic virtues. This is to say, a belief B for subject $S$ can be justified even if $S$ did not acquire $B$ through one or more of the epistemic virtues. In order to undermine Sosa's virtue condition, I will offer a case in which an epistemic subject $S$ has a justified belief $B$, but did not acquire $B$ through the use of one or more of the epistemic virtues. The case I will present is especially damaging to Sosa because, as I will further argue, Sosa ought to accept (given his commitment to a direct acquaintance account of epistemic justification) that in the troubling case $S$ 's belief B is justified even though it was not acquired through the exercise of one or more of the epistemic virtues. But of course Sosa cannot accept this result (which I will suggest he is committed to accepting) given his endorsement of the virtue condition. Sosa is caught, I will argue, on the horns of a nasty dilemma.

Before delving into my proposed case that explicates the major difficulty for Sosa, a few points of clarification are worth making. Sosa accepts that when a person under normal conditions clearly perceives a three-speckled-hen and forms the non-inferential unmediated belief that, "my experience is three speckled," then the belief is foundationally justified. A normal human epistemic subject's "introspective report" of her three-speckled experience is foundationally justified, whereas alternatively a normal human epistemic

\footnotetext{
${ }^{2}$ Sosa, 170

${ }^{3}$ Sosa, 156
} 
subject who perceives a forty-eight-speckled hen and forms (through a guess) that, "my experience is forty-eight speckled" has an unjustified belief. But why is the belief in the three-speckled case justified, while the belief in the forty-eight speckled case is unjustified? After all, the hen in the forty-eight-speckled case really did have fortyeight speckles and these speckles really did "present themselves" to the epistemic subject in question. Why is the belief that the hen has three speckles foundationally justified, while the belief that the hen has forty-eight speckles not epistemically justified?

Richard Feldman explains Sosa's attempt to distinguish the above two cases in the following manner:

Sosa says that to explain the difference we must appeal to more than the following three items, (a) the phenomenal character of the experience, (b) the propositional content of the occurrent thought as one judges the images to contain so many speckles, (c) the fit between the phenomenal character and the propositional content. Sosa proposes that the difference between a justified introspective report and an unjustified introspective report is that the former is safe and virtuous. To say that a judgment is safe is to say that, "in the circumstances not easily would one believe as one does without being right." And a belief is virtuous provided it is "derived from a way of forming beliefs that is an intellectual virtue, one that in our normal situation for forming beliefs would tend to give us beliefs that are safe."

Thus, for Sosa the three-speckled belief qualifies as a justified belief because it was formed safely through the exercise of an epistemic virtue, while the forty-eight-speckled belief is not justified because it was not formed through such an exercise. Guessing, which is the belief-forming process of the subject who believes the hen has fortyeight speckles, is not a way of forming beliefs that would tend to produce safe beliefs and hence the forty-eight- speckled belief fails Sosa's virtue condition of justification. Note that the above still holds, for Sosa, even if all the hens in the world just happen to have forty-eight speckles (perhaps because of some strange natural law). The guess that the hen has forty-eight speckles would be safe (and as such sat-

${ }^{4}$ Richard Feldman, "Foundational Justification," in Ernest Sosa and his Critics, ed. John Greco, (MA; 2004) pp. 49-50. 
isfy Sosa's safety condition), but the belief (even though safe) would still fail the virtue condition as guessing does not tend to form safe beliefs. ${ }^{5}$

Now, having briefly considered Sosa's account of epistemic justification, I will provide a case that presents a troubling dilemma for Sosa's account.

\section{Consider the following two cases:}

Case One (Jeremy): Jeremy is a normally functioning human epistemic agent. When he looks at a speckled hen he can only grasp three speckles in an unmediated non-inferential fashion. If the number of speckles is more than three, then Jeremy must count to arrive at the correct number of speckles. On his thirtieth birthday, Jeremy wakes up and finds himself with a new and strange "rainman" like ability. Jeremy now looks at a hen with forty-eight speckles and in an unmediated non-inferential fashion believes in a highly reliable fashion that the hen has forty-eight speckles. It's amazing, Jeremy thinks! Further, Jeremy is as confident that his belief about the forty-eight speckles is true as he was about his three-speckled belief being true before he turned thirty.

Case Two: (Jeremy*) Consider case one as it is and add the modification that Jeremy's new found ability "comes and goes" in an unpredictable (but recognizable) fashion. It is as if his rainman-like ability flickers. Jeremy* can realize when his "rainman" ability is turned on by merely looking at a many-speckled hen. If he looks at the hen and thinks to himself, "nope, I just cannot say how many speckles without guessing," then the ability is "turned off," but if he thinks to himself, "yep, I see it right in front of me and as clear as day that hen has forty-eight speckles," then the "rainman" ability is "turned on." Here we might compare Jeremy* with a person whose perceptual faculty comes and goes or with a person whose memory faculty comes and goes.

Now let us suppose that Jeremy, after his thirtieth birthday, is looking directly at a hen under good lighting conditions and forms the unmediated non-inferential belief that the hen has forty-eight speckles.

${ }^{5}$ Feldman in his Sosa and his Critics piece does a very nice job of drawing out this important point. 
Jeremy's belief, in such circumstances, is justified because the belief is "epistemically analogous" to (normal) Jeremy's foundationally justified belief that the hen has three speckles. An argument to this effect would proceed accordingly:

(1) Jeremy's pre-thirty belief that the hen has three speckles is epistemically justified.

(2) Jeremy's post-thirty belief that the hen has forty-eight speckles is epistemically analogous to his pre-thirty belief that the hen has three speckles.

(3) Jeremy's post-thirty belief that the hen has forty-eight speckles is epistemically justified.

A normal human epistemic subject, for instance Jeremy when he is twenty-nine, has a reliable faculty of perception. And Jeremy uses his reliable faculty to recognize, in an unmediated and non-inferential fashion, that the hen has three speckles. As I noted earlier, Sosa, rightly I think, endorses the claim that Jeremy is foundationally justified to believe that the hen has three speckles. This is not in dispute.

Jeremy, after turning thirty, has this same ability of unmediated and non-inferential perceptual recognition (and the ability is no less reliable). It is just that after Jeremy turns thirty his ability of perceptual recognition is significantly supplemented (it is much more sensitive to external stimuli). And if we are to accept that Jeremy (when he is twenty-nine) has a justified three-speckled belief, then it seems to follow that Jeremy (when he is thirty) has a justified fortyeight-speckled belief. ${ }^{6}$ The two beliefs are epistemically analogous in that both of them were formed via a reliable, unmediated, and non-inferential belief forming process. The two beliefs are indeed epistemically analogous.

Consider that Sosa would have little difficulty accepting the suggestion that upon perceiving (under normal conditions) a hen with two speckles, that Jeremy comes to the unmediated non-inferential foundationally justified belief that, "the hen has two speckles." The two-speckled belief is epistemically analogous to the three-speckled

${ }^{6}$ No doubt, pre-thirty Jeremy does not form the justified belief that the hen has forth-eight speckles. Both Sosa and I agree to this. 
belief, nothing relevant to epistemic justification has changed. But this, I offer, is also true in the forty-eight speckled belief formed by Jeremy after his thirtieth birthday. Of course, Jeremy's faculty of perception (or some similarly related faculty) went through a dramatic improvement, but this should not rule out the forty-eight speckled belief as being epistemically analogous to the three-speckled belief. After all, people can learn to get better (in ways that are both safe and virtuous) at grasping perceptual content in an unmediated and non-inferential fashion. They can also get hit on the head and get better or worse at such things. In fact, I would highly suspect that most normal human epistemic subjects have learned (typically in their childhood development) to non-inferentially grasp perceptual content (and hence formed justified beliefs) that they were unable to previously grasp (in their infancy, for instance) in both a safe and virtuous fashion. There is no reason why Jeremy must "remain stuck" at only being able to be foundationally justified in believing that the hen has three speckles (as opposed to say four, six, or, for that matter, fortyeight speckles). The point is that our epistemic faculties can change through learning, age, or happenstance (for better or worse), and the plastic nature of our epistemic faculties allows the content of what we may be said to be foundationally justified in believing changes as well.

Let us now consider more closely Jeremy's forty-eight-speckled belief. Does this forty-eight-speckled belief satisfy Sosa's safety condition? The answer here is yes, Jeremy's forty-eight-speckled belief does satisfy Sosa's safety condition. Jeremy's belief $P$ (that the hen has forty-eight speckles) is safe because it is the case that in his circumstances Jeremy would (most likely) believe $P$ only if $P$ were the case. Jeremy believes that the hen has forty-eight speckles because the hen does have forty-eight speckles and Jeremy grasps this fact in a reliable, unmediated, and non-inferential fashion. Jeremy's rainman-like ability allows him to form safe beliefs about many-speckledhens. Further, if Jeremy's forty-eight- speckled belief is epistemically analogous to his three-speckled belief, then there is no good reason at all to suspect that the three-speckled belief would be safe (a view Sosa is committed to) while the forty-eight speckled belief would fail to be safe.

Now let us turn to Sosa's virtue condition and ascertain whether Jeremy's forty-eight-speckled belief will count, for Sosa, as meeting 
this condition. Recall that Sosa's virtue condition states: "B is a justified belief only if B is a belief acquired through the exercise of one or more epistemic virtues." Here we should ask, "is Jeremy's fortyeight-speckled belief acquired through one or more of the epistemic virtues?" (This question sets up the beginnings of a dilemma for Sosa which will come to fruition when we consider Jeremy ${ }^{\star}$, but before exploring this possibility we must allow Sosa to respond to the question on the table.) Sosa could maintain that the answer to this question is no; that is Jeremy did not acquire his forty-eight-speckled belief through one or more of the epistemic virtues. But, if this is the case, then Sosa must conclude (given his treatment of epistemic virtue as a necessary condition of justified belief) that Jeremy's fortyeight-speckled belief is not justified. But this, as I suggested above, is false and hence not a viable option for Sosa to take.

But Sosa need not reply negatively to the above question, and be straddled with the conclusion that Jeremy's forty-eight-speckled belief is not justified (and this would be a very bad result indeed, as he is committed, I have argued, to maintaining that Jeremy's fortyeight-speckled belief is justified). Sosa could answer yes to the question and as such allow that Jeremy acquired his forty-eight-speckled belief through one or more of the epistemic virtues. Recall that for Sosa a belief is virtuous provided it is "derived from a way of forming beliefs that is an intellectual virtue, one that in our normal situation for forming beliefs would tend to give us beliefs that are safe." ${ }^{8}$ It does seem as if Jeremy forms his beliefs about the forty-eight-speckled hen by the exercise of epistemic virtue in the same fashion that he formed his beliefs about three-speckled hens before his thirtieth birthday. And, as such, Sosa can argue that Jeremy (though odd in his rainman ability) does in fact form his foundationally justified fortyeight-speckled belief in a fashion consistent with both his safety and virtue conditions.

Here the distinction between the cases involving Jeremy and Jeremy ${ }^{*}$ becomes quite relevant. I grant when considering Jeremy, Sosa could likely advance a plausible case for suggesting that he acquired his justified forty-eight-speckled belief as a result of one or more intel- 
lectual virtues. And, as such, we should have no difficulty (consistent with Sosa's account) suggesting that Jeremy's belief that the hen has forty-eight speckles is a (foundationally) justified belief. Jeremy (for some strange reason due to happenstance) forms a stable rainmanlike perceptual faculty and thus might be plausibly said to both meet the virtue condition and be foundationally justified in his forty-eightspeckled belief.

The serious difficulty for Sosa comes when we carefully consider Jeremy*. Let us grant, in plausible fashion, that Jeremy"s "flickering" rainman-like faculty can be constructed in such a way that will satisfy Sosa's safety condition. That is, when Jeremy"s rainman-like faculty/ability is "turned on" it allows him to form the ummediated non-inferential belief that the hen has forty-eight speckles in a safe fashion. Sosa could attempt to resist this move and accordingly try to press the point that Jeremy"s belief (when the rainman faculty is "turned on") will not be safe, but this move would, I suspect, fail. Recall that Sosa is committed to the view that, "to say that a judgment is safe is to say that in the circumstances not easily would one believe as one does without being right." cases are set up specifically to ensure that Sosa's safety condition is met in both cases.

Given that the safety condition is satisfied we can now turn toward asking whether Jeremy* acquires (when his rainman faculty is turned on) his forty-eight-speckled belief through one or more of the epistemic virtues. Sosa could end the discussion here and say, "no, Jeremy"'s belief fails the virtue condition and thus he fails to have the (foundationally) justified belief that, "the hen has forty-eight speckles." But Sosa cannot rightly advance this answer to the question because Jeremy*'s forty-eight-speckled belief (when his rainman faculty is turned on) is justified, and if Sosa's virtue condition gives us the result that Jeremy"s forty-eight speckled belief is, under these conditions, unjustified then so much the worse for Sosa's virtue condition. Consider the following argument for the claim that Jeremy"s forty-eight-speckled belief is justified:

(1) Jeremy's forty-eight-speckled belief is justified.

(2) Jeremy*'s forty-eight-speckled belief in case two (the case

${ }^{9}$ Sosa, 138 
where his rainman faculty/ability is turned on and he recognizes that it is turned on) is epistemically analogous to Jeremy's forty-eight-speckled belief in case one.

(3) Jeremy"s forty-eight-speckled belief is justified.

The first premise was argued for earlier in the paper, and its result seems undeniable (at least undeniable for one who-as Sosa doesaccepts a direct acquaintance view of epistemic justification). Jeremy's forty-eight-speckled belief is epistemically analogous to his prethirty, three-speckled belief. His abilities obviously become sharper, but the same reasons for thinking that pre-thirty Jeremy was justified in his three-speckled belief (a claim Sosa assents to) remain in the post-thirty forty-eight-speckled case. Additionally, premise two is highly plausible. Just imagine Jeremy peering at a forty-eightspeckled hen alongside his Jeremy ${ }^{*}$ counterpart (under the conditions where Jeremy*'s rainman ability is turned on). The two epistemic subjects, under these conditions, are epistemically identical. Both agents grasp, in an unmediated and non-inferential fashion, the experience of being appeared to forty-eight speckledly in the same fashion. It would be absurd to suggest that Jeremy's belief (the hen has forty-eight speckles) was justified while Jeremy"s belief with the same propositional and experiencial content was unjustified.

Sosa does have a reply that he can offer here in response to my above defense of premise two. Sosa could suggest that Jeremy* forms his forty-eight-speckled belief in a different, nonfoundational, way involving his belief that his rainman-like ability is switched on, thereby utilizing this belief as an inference that contributes to the forty-eight-speckled belief. This reply from Sosa nicely challenges whether Jeremy"s forty-eight speckled belief is, after all, foundationally non-inferentially justified. Let us add to the case (to address this worry) that Jeremy* has had his flickering rainman-like ability for quite a well, and as such his recognition that his special ability is turned on (when he looks at a hen, for instance) is almost second nature to him. This is to say he does not consciously deliberate as to whether his ability is turned on (or off for that matter) before looking at a hen. Jeremy* does not reflectively base his belief that the hen has forty-eight speckles on the further belief that his rainman-like ability is turned on, and thus I do not think Sosa's above worry is dangerously problematic to the second premise of my argument. 
Consider the case of a normal human epistemic subject who noninferentially grasps in an unmediated fashion that the hen she is looking at has three speckles. Sosa accepts that such a belief is foundationally justified. Now add to this case that the epistemic subject also has the belief (not occurring to her often) that her faculty of perception is reliable. Surely, this case is far from extraordinary. Does such a belief about the reliability of her perceptual faculty, on the part of a normal human epistemic subject, suggest that her beliefs using such a faculty are ruled out from being non-inferentially foundationally justified? I would suspect not, especially when this normal epistemic subject is not actively contemplating her belief that her faculty of perception is reliable. Something like the following principle of inference might be helpful here:

Inference Principle (IP): An epistemic subject $S$ forms a belief $P 1$ in an (conscious and epistemically significant) inferential process utilizing another belief P2 only if $S$ consciously (actively) weighs or considers $P 2$ in her process of forming belief $P 1$.

There is an important epistemic question here regarding what counts (or doesn't count) as an epistemic subject forming her beliefs through an inferential process involving another belief. Tentatively, I have suggested that the Jeremy ${ }^{\star}$ case can be thought of in such a fashion (consistent with IP) that allows his forty-eight speckled belief to be formed in a non-inferentially unmediated foundationally justified manner.

Notice, importantly, that Jeremy* realizes if his rainman abilities are working by simply looking at a many-specked-hen. Before he looks at the many-speckled-hen he does not consciously deliberate as to whether his rainman abilities are "turned on," but as soon as he looks at a many-speckled-hen he knows right away if his rainman-like ability is working. If the ability is "turned on" then Jeremy* forms the reliable, unmediated, and non-inferential belief that the hen has forty-eight speckles, if the ability is turned off, then Jeremy ${ }^{\star}$ forms the belief that the hen has plenty of speckles but that he cannot tell how many speckles the hen has. (Notice that all this is consistent with the above stated IP.) Whether Jeremy*'s belief is inferentially formed is a separate matter from whether he has a defeater for his belief upon perception of a hen. Jeremy*, like Jeremy, has a reliable 
memory, and as such he knows of his intermittent rainman abilities. Jeremy* cannot predict when his special ability is working until he looks at a hen, but he does know that the ability comes and goes. Thus, there is no obvious defeater present for Jeremy*'s belief that the hen has forty-eight speckles.

Consider that Jeremy* is having a day where his rainman-like abilities are "turned on." And thus he looks at a hen and forms the foundationally justified belief that the hen has forty-eight speckles. Sosa could attempt to argue here that Jeremy"s, like Jeremy's, belief satisfies his virtue condition (and as such has met this necessary condition of justification). Sosa's difficulty is that he cannot plausibly advance this suggestion nearly as easily as he might be able to do so in the Jeremy case. This is because Jeremy ${ }^{*}$ has a wavering and flickering disposition and these types of dispositions do not lend themselves well to an analysis of virtue. Virtues, and I think Sosa would agree, are well-rooted dispositions and do not turn on and off like Jeremy*'s intermittent rainman-like disposition. The virtues, be they moral or epistemic, do not just come and go; they must be "part of us, of our character" in a stable sense to be aptly called virtues.

If the above analysis of virtue, following in the Aristotelian tradition, is correct, then Sosa is confronted with a serious problem. This is because Jeremy ${ }^{*}$, even though he is foundationally justified to believe that the hen has forty-eight speckles, does not acquire through the exercise of one or more epistemic virtues the justified belief that the hen has forty-eight speckles. Jeremy*'s rainman-like faculty (and dispositions) are simply too wavering and unstable to satisfy Sosa's virtue condition. Here we see exactly where Sosa is stuck on the horns of a nasty dilemma. He could try to argue that Jeremy"'s forty-eight-speckled belief is not (foundationally) justified, but, as I argued earlier, this approach would likely fail, or he could try to argue that Jeremy"s forty-eight-speckled belief satisfies his virtue condition, but this approach (just so long as virtues are inconsistent with unstable dispositions) will also likely fail. As such Jeremy* represents a counterexample to Sosa's claim that, "B is a justified belief only if B is a belief acquired through the exercise of one or more epistemic virtues." 10

${ }^{10}$ Sosa, 156 
Consider, for a moment, moral, as opposed to epistemic or intellectual, virtue. When we think of a courageous person (say, for instance, Sally), we note that Sally has a very strong and stable disposition to act bravely. Would we think Sally possessed the virtue of bravery if we noted that she has the bravery disposition "turned on" at intermittent times? Let us add that Sally knows, via her good memory, that her "moral virtue" flickers on and off, and further that she can "sense," when she is confronted with the right situation, when her disposition to act bravely is "turned on." Now consider that on a random Tuesday Sally possesses the disposition of being brave. Is Sally brave on Tuesday-that is does she posses the moral virtue of bravery during the Tuesday when her virtue is "turned on"?" While I suspect that different plausible answers could be given to this question, I offer that Sally is not brave (in the sense of exercising the moral virtue of bravery) in the case thus described. In order for Sally to possess the moral virtue of bravery, she would need to have a stable disposition to act bravely, and she clearly lacks this stable disposition.

What then do we say of Sally's actions on the Tuesday described above? I would suggest that Sally, in that case, is acting as the virtuous person would act, but that she herself lacks the moral virtue of courage. Aristotle renders a similar analysis of moral virtue, and it strikes me as a suggestion with quite a bit of promise. People who lack moral virtue often act in ways that are like (if not qualitatively identical) to those of people who actually possess moral virtue. Perhaps the above consideration will help us better analyze Jeremy*. Tentatively, it might be fruitful to consider that Jeremy* acts (when he forms the justified forty-eight-speckled belief) as the epistemically (or intellectually) virtuous person would act, but that he himself (like Sally above) lacks virtue (in the relevant sense). The idea here is that one who fails to possess virtue (of either the moral or epistemic variety) can nonetheless act as the virtuous person would have acted but that a mere acknowledgement of this will not demonstrate that virtuous action qua virtuous action has taken place. Jeremy*, by forming the justified belief that the hen has forty-eight speckles in a non-inferen-

"I ask the question this way because it is fairly clear that Sally does not possess the virtue of bravery when the disposition is "turned off." 
tial unmediated fashion, acts just as his counterpart Jeremy would have acted. The difference is that Jeremy is virtuous, unlike Jeremy ${ }^{*}$, because Jeremy's (mental) action (belief that the hen has forty-eight speckles) was produced by an enduring stable disposition, while Jeremy"'s was not. As such, it might be right to suggest that Jeremy* believes as the epistemically virtuous person would believe, but that he himself fails to fulfill Sosa's epistemic virtue condition.

What can Sosa say in response to the above charge? One possible reply is to offer an account of how Jeremy"s belief is, after all, one formed through the exercise of an epistemic virtue. Above I expressed my skepticism regarding such a move, but Sosa could nonetheless suggest the following: on the occasions when Jeremy"s rainman-like ability is working, he does in fact form safe beliefs through a process of belief formation that utilizes an epistemic virtue. Jeremy ${ }^{*}$ has a good memory and this allows him to use, albeit in an intermittent fashion, his rainman ability in a responsible, reliable, and (importantly) virtuous fashion. His beliefs are indeed formed through a virtuous belief-forming process and hence my account renders the right result in allowing us to count Jeremy"'s belief as (a) foundationally epistemically justified, (b) fulfilling the safety condition, and (c) fulfilling the virtue condition.

How plausible is Sosa's above attempt to suggest that Jeremy"s forty-eight-speckled (justified) belief coheres with his virtue condition? A problem with assessing just how plausible a case Sosa can offer here is that in Epistemic Justification, Sosa does not offer a protracted treatment of either his virtue condition or of epistemic (intellectual) virtues in general. In fact, it would not be unfair to accuse Sosa of offering a putrid account of epistemic virtue. He does note, however, that, "knowledge (justification) requires one's belief to be not only safe but also virtuously sustained, through the use of a reliable ability or faculty, through an intellectual virtue."12 Can we say that Jeremy"s forty-eight-speckled belief is virtuously sustained through an intellectual virtue? Perhaps not, especially when we consider that Jeremy"s forty-eight-speckled belief might (given the intermittent status of his ability) "turn off" in the middle of his viewing the manyspeckled-hen. Here we see that it will be much easier for Sosa to

${ }^{12}$ Sosa, 139 
maintain that Jeremy meets his virtue condition than it will be for him to maintain that Jeremy ${ }^{*}$ does so. To Sosa's credit he does admit in a footnote at the end of his above thought that, "In a fuller treatment these notions need to be clarified, and their virtues displayed more fully in a dialectical interplay between main competitors." ${ }^{13}$ One worries that, despite this admission, Sosa's treatment of his virtue condition fails to be interestingly informative.

One significant problem with Sosa's virtue condition is that it runs the serious risk of being an ad hoc device that does little more than "fill in the blank" for the "thing" when contributing to the safety of a belief produces epistemic justification. One spies this possibility rearing its head when Sosa notes, "It [a belief] is virtuous because one's belief derives from a way of forming beliefs that is an intellectual virtue, one that in our normal way for forming such beliefs would tend strongly to give us beliefs that are safe." ${ }^{4}$ Here we must ask, what does Sosa's virtue condition add to his safety condition (or to his account of epistemic justification more generally)? A charitable reading suggests that Sosa's virtue condition is attempting to point in the direction of "that thing" which, "tends strongly to give us beliefs that are safe." Sosa, of course, calls "that thing" intellectual virtue, but beyond offering this label, not much more in regard to "that thing" (aside from Sosa's suggestion that it produces safe beliefs) is forthcoming in Sosa's account. ${ }^{15}$

Sosa must do better, I offer, than suggest that Jeremy"s fortyeight-speckled belief meets the virtue condition just in case his belief is formed through a reliable belief-forming process that produces safe beliefs. If this is all Sosa wants to say, then one is at a loss to see what substantial work the virtue condition is adding to Sosa's account. Why not simply suggest that the virtue condition really just amounts to the "appropriately try" condition. That is to suggest that

${ }^{13}$ Sosa, 139 (fn.16)

${ }^{14}$ Sosa, 138-9

${ }^{15}$ This is one of the most frustrating aspects of Sosa's account of epistemic justification. One would like so much more than he offers in the way of a treatment of epistemic virtue. Sosa's treatment of his virtue condition is so obscure that it makes challenging the idea rather difficult. I am trying to piece together as much of his account of the virtue condition as I can without being unfair to Sosa. 
a necessary condition of subject $S$ forming belief $P$ (in a justified fashion) is that $S$ "appropriately try" to ensure that her belief is safe. Of course, this "appropriately try" condition does not have the same ring to the ear as a "virtue condition," but nonetheless one wonders how these two conditions really do, for Sosa, relevantly differ. What is it about intellectual virtue qua intellectual virtue, for Sosa, (not just solely as a means of forming safe beliefs) that serves as a condition that justifies belief? Sosa never adequately tells us, and this lack of explanation opens him to the charge that the virtue condition functions as little more than a clause that merely serves as an ad hoc device that allows him to loosely "fill in the blank" for the "thing" that when contributing to the safety of a belief produces a necessary component of justification. ${ }^{16}$

I have suggested that the intellectual virtues (however they turn out to be understood) must be stable dispositions, and that Sosa's suggestion of "knowledge (or justification) to be virtuously sustained through the use of a reliable faculty, through an intellectual virtue" is consistent, in at least broad outline, with this thought. Any proper conceptual treatment of epistemic/intellectual (or moral) virtue must involve, in the least, an analysis of a stable disposition of one's character. But can we offer a plausible account of how Jeremy*'s forty-eight-speckled belief is virtuously sustained, through the use of reliable faculty, through an intellectual virtue? Jeremy*'s rainmanlike disposition is not, itself, stable, but perhaps more can be said here to help Sosa. Below is a rough outline of Sosa's best reply to this challenge.

Jeremy* knows that his rainman-like faculty is itself unstable, but we could suggest that Jeremy* has a stable disposition to exercise his rainman-like faculty only when he knows the faculty lends itself to the safe creation of beliefs. Viewed in this light, the relevant disposition

${ }^{16}$ As one might be able to ascertain from the tenor of these last comments I am skeptical that epistemic justification is dependent upon a virtue condition. My own position, in broad outline, is that epistemic justification depends upon a "safety condition" and a "responsibility condition". I suspect that deontological accounts of justification (especially when meshed with a Sosa-like safety condition) can go much further and offer must more plausible accounts of epistemic justification than can accounts of epistemic justification that rely on "virtue conditions." 
that Jeremy* exhibits is quite stable (like an intellectual virtue should be). The epistemic faculty that Jeremy"s disposition "maps up with" is unstable; (but no worry) Jeremy"s disposition (his intellectual virtue) is quite stable. The key to Sosa's move here is to tell a story of how the intellectual virtues should be considered in a relativized manner consistent with the dispositions of agents who find themselves in various epistemic situations. The epistemically virtuous normal human epistemic subject must be considered differently than Jeremy, and likewise Jeremy (or at least Jeremy's intellectual (epistemic) dispositions must be considered differently than Jeremy*'s dispositions. In order to assess whether any particular epistemic subject meets the virtue condition (with respect to any particular belief), so Sosa could argue, we must consider the specific elements of the case at hand and ask ourselves, does subject $S$ form his beliefs consistent with the "manifestation" of a cognitive virtue? And as I noted above, Sosa can make the case that Jeremy* (by forming a type of stable disposition) does exactly this. Thus, I do accept that it is possible for Sosa to advance a positive case for Jeremy*'s forty-eight-speckled belief to meet the demands of his virtue condition.

Is Sosa out of the woods? Does he escape the horns of the dilemma which I have tried to impale him on throughout this paper? Not so fast. First, it is not obvious that his (best) above attempt to reconcile Jeremy*'s forty-eight speckles belief with his virtue condition will succeed. It is certainly not clear that the intellectual virtues (however we plausibly understand them) should be relativized in a fashion that would allow Sosa to suggest that Jeremy*'s disposition to believe that the hen has forty-eight speckles (when he non-inferentially grasps this) meets his virtue condition. Just as plausible a move, I suggest, is to claim that Jeremy* believes as the virtuous person (Jeremy) would believe, but that he himself does not exhibit the intellectual (epistemic) virtue given the "intermittent status" of his rainman-like ability. Like Sally, in our earlier moral case, it is not enough that she has the "right dispositions" when her moral sense is switched on, in order to exhibit the virtues her actions must flow from a stable morally virtuous character (and the flickering nature of this character) is a strong indication that Sally lacks virtue. Virtue is not a "sometimes" type of thing; it is much closer to an all-or-nothing expression of one's character. Perhaps Sosa could respond here by saying the following: 
Oh, I was not arguing that Jeremy ${ }^{*}$ was epistemically virtuous generally, instead I simply suggested that his (particular mental act) forming the forty-eight-speckled belief meets my virtue condition.

This type of response nicely illustrates just how nuanced a treatment of (epistemic) virtue can become, and it certainly goes far beyond the treatment of virtue that Sosa offers in Epistemic Justification. But this move by Sosa can be given a criticism which runs as follows:

Sosa, this reply is exactly the type of thought that confuses a virtuous act from an act that would have been virtuous had it been performed by a virtuous person. Virtuous acts (or mental acts such as forming beliefs) cannot be done by people who are not virtuous. And Jeremy*'s, by having an intermittent rainman-like epistemic ability, fails to meet this burden.

The dialectic could continue here for quite some time, but at this juncture I merely want to press the point that Sosa's defense of Jeremy*'s forty-eight-speckled belief as meeting his virtue condition is no easy sell.

But even if Sosa can escape the dilemma I have presented him with, his virtue condition suffers from more general problems. Earlier I expressed the worry that Sosa's virtue condition struggles from an ad hoc concern. That is, whenever a reliable belief-forming process tends to produce safe beliefs, Sosa can just seem to point to "that" and suggest that "it" meets the virtue condition. Just how seriously this concern falls prey to ad hoc objections I will not explore here, but the worry does exist and it strikes me as a serious difficulty for Sosa's virtue condition independently of whether or not he can account for the Jeremy* case.

I would like to end by noting that there is something right about Sosa's desire to incorporate a condition in his account of epistemic justification that speaks to the "appropriate epistemic attitude" of the epistemic subject. But I offer that his virtue condition is the wrong way to go about considering this important aspect of epistemic justification. If we want to express a desire to clearly capture a workable notion of an appropriate epistemic attitude we would be best to pursue the notion of epistemic responsibility (as opposed to epistemic 
virtue). Jeremy and Jeremy* are both forming their safe beliefs that the hen has forty-eight speckles in a responsible fashion, and it is this key notion of epistemic responsibility(they are both appropriately trying to engage in safe beliefs) which better explains (as opposed to Sosa's virtue condition) why the two very different epistemic subject both have the justified belief that the hen has forty-eight speckles. Part of the reason why talk of epistemic responsibility is superior to talk of (epistemic) virtue is because responsible actions (beliefs) can be parsed up into discrete individual components much easier. A person can believe responsibly on Tuesday and irresponsibly on Wednesday (I can appropriately try to form safe beliefs in respect to belief $X$ but fail in this charge in respect to belief $Y$ ), but the same parsing might not be available in the case of virtuous belief-forming processes.

In conclusion, I have used this paper as an opportunity to challenge Sosa's virtue condition with a counterexample (based upon an intermittent rainman case) that sought to impale Sosa on the horns of a dilemma. In considering Sosa's replies I offered a means in which Sosa might be able to escape the horns of my proposed dilemma (but this escape is not a case of clear sailing past the horns for Sosa). Additionally, I explored the worry that Sosa's virtue condition is both under-informative as well as an open door for ad hoc trouble. Toward the end of the paper I defended, in broad outline, the notion that the key element of an appropriate epistemic attitude to which Sosa is trying to capture is best (and most clearly) done through talk of responsibility as opposed to talk of virtue. Whether Sosa can defend the virtue condition in light of these worries is an interesting consideration which I will not pursue further than I already have. This paper has shown that much more of a defense, on Sosa's and others part, is needed if the virtue condition for epistemic justification is to survive some very pressing questions. ${ }^{17}$

\section{References}

Aristotle, Nicomachean Ethics, ed. and trans. Terrance Irwin (Hackett, 1999).

${ }^{17}$ I thank Peter Markie for offering extremely helpful comments on drafts of this paper. 
Bonjour, Laurence and Ernest Sosa. Epistemic Justification: Internalism vs. Externalism, Foundations vs. Virtues (MA; 2003).

Feldman, Richard. "Foundational Justification," in Ernest Sosa and his Critics, ed. John Greco, (MA; 2004) pp. 49-50.

Sosa, Ernest. "Knowledge and Intellectual Virtue" Monist, 68 (1985): 224-245.

Sosa, Ernest. "Proper Function and Virtue Epistemology" Nous, 27 (1993): 51-65. 